\title{
Time Series Trend and Variability Analysis of Temperature and Rainfall in West Shewa Zone of Oromia, Ethiopia
}

Daniel Assefa ( $\sim$ danasse19@gmail.com)

Ambo University Institute of Cooperative and Development Studies https://orcid.org/0000-0002-18549830

Mesfin Mengistu

Ambo University

\section{Research}

Keywords: Coefficient of variation, Mann Kendall test, Rainfall, Temperature, Variability

Posted Date: April 26th, 2021

DOl: https://doi.org/10.21203/rs.3.rs-410118/v1

License: (c) (i) This work is licensed under a Creative Commons Attribution 4.0 International License.

Read Full License 
Time Series Trend and Variability Analysis of Temperature and Rainfall in West Shewa Zone

of Oromia, Ethiopia

Daniel Assefa ${ }^{1} \&$ Mesfin Mengistu ${ }^{2}$

1School of Natural Resource Management, Ambo University

*corresponding author: e-mail: danasse19@gmail.com OR frewa2015@gmail.com,

Cell phone: +251913337217 OR +251972203407

\begin{abstract}
Background

The paper focus on time series trend and variability analysis of observed rainfall and temperature records from 16 stations during 1985-2015.
\end{abstract}

\title{
Results
}

Both the summer and annual rainfall have an increasing trend but not statistically significant. Regards to variability, low to very high levels of variability were recorded according to the seasons and annual rainfall, whereas, moderate to extremely high levels of variability were observed. The result of the Mann Kendall test portrays that the mean minimum temperature was raised by $0.05{ }^{\circ} \mathrm{C}$, while the maximum temperature was increased rose by $0.03{ }^{\circ} \mathrm{C} / 30$ years. The monthly maximum temperature also shows an increasing trend with the lowest record during August $\left(22.05{ }^{\circ} \mathrm{C}\right)$ and the highest in the March $\left(26.49{ }^{\circ} \mathrm{C}\right)$ except in the month of November and December. Similarly, an increasing trend was observed with a mean monthly minimum temperature with the lowest mean of $8.42 \mathrm{C}^{\circ}$ in December and the highest mean of $11.12{ }^{\circ} \mathrm{C}$ recorded in April. Besides, a low level of variability was seen both in the case of minimum and maximum temperature were observed in all months.

\section{Conclusions}

Therefore, since the observed trends of both temperature and total rainfall show abnormal shifts, there is an urgent need for policymakers to design systematic planning and management activities to rain-fed agriculture.

Key words: Coefficient of variation, Mann Kendall test, Rainfall, Temperature, Variability

\section{Background of the study}

The global climate is changing and this change is apparent across a wide range of observations. Intergovernmental Panel on Climate Change (IPCC) disclosed the significant increase in atmospheric concentration of greenhouse gases (GHGs), mainly carbon dioxide (CO2) from 280 to $360 \mathrm{ppmv}$, methane (CH4) from 700 to 1720 ppbv and nitrous oxide (N2O) from 275 to 310 ppbv since pre-industrial times (about 1750 AD) (IPCC, 1995). For such alarming rates of increase in the concentration of GHGs in the atmosphere the industrial revolution launched during $17^{\text {th }}$ century is recognized as the main reason than any other possible sources like natural process. Because for thousands of hundreds of years' climates of our planet earth was normal, that means natural process has no significate impact for climate change. As a result, the observed increase in global average temperature since the mid-twentieth century is attributed to the observed increase in anthropogenic GHGs concentrations (IPCC, 2007). Moreover, the long-term warming trends since pre-industrial times is continued and the observed global mean surface temperature for the decade $2006-2015$ was $0.87^{\circ} \mathrm{C}$ higher than the average over the $1850-1900$ periods (IPCC, 2018). Such increase in the atmospheric temperature is understood as responsible for global warming and wider change in the global and regional climate and observable impact on land ecosystems of this plant (Patle and Libang, 2014).

Birhanu et al. (2017) noted that warming in the entire climate system can result in very large corresponding changes in the occurrence of climate extremes. Among this impact due to global warming greater climatic volatility such as changes in precipitation patterns and increased frequency and intensity of extreme weather events like frequent drought, damaging flood, affecting heat waves and a rise in mean global sea levels are mentioned as the common impacts of global warming (Prasada-Rao \& Solomon, 2014). Zerihun (2012) also stated that progressive change in the global climate is estimated to alter the natural system in many ways like the frequency of extreme weather events would increase, sea levels would rise, ocean currents would reverse, and precipitation patterns would change. Besides, the impact of climate change is significant in influencing long-term rainfall patterns that has also its own 
effect on the availability of water, along with the danger of increasing occurrences of droughts and floods (Jain and Kumar, 2012). Changes in the amount of rainfall have tremendous impact on the livelihood of the rural people especially in developing countries, since their only means of livelihood, i.e., agriculture, largely depends on seasonal rainfall (Gogoi, 2019). As a result of this climate change is becoming a broad area of research; the increase in temperature and changing pattern of precipitation deserves urgent and systematic attention as it will affect many aspects of living particularly in the poor countries (Dore, 2005).

In this perspective, Africa is considered as the most vulnerable and disproportionately affected region in the world in terms of climate change (Zerihun, 2012). In Africa temperature, are projected to rise faster during the $21^{\text {st }}$ Century, with temperature extremes breaching levels experienced today by $2{ }^{\circ} \mathrm{C}$ by 2050 and $4-6{ }^{\circ} \mathrm{C}$ by the end of the $21^{\text {st }}$ Century in tropical western Africa and the Sahel. Changes to rainfall regimes are more uncertain, but indications from global climate modeling exercises are that southern African will become drier and eastern and western Africa will become wetter, with rain falling more intensely and bringing an increase in the risk of floods (United Nations Development Program, 2018). In addition, varying trends of both increasing and decreasing patterns of rainfall, but significant increasing trends in maximum temperature (up to $1.9{ }^{\circ} \mathrm{C}$ ) and minimum temperature (up to $1.2{ }^{\circ} \mathrm{C}$ ) were concluded for virtually the whole region of East Africa (Solomon et al. 2019). Furthermore, the projected increase in the surface temperature of sub-Saharan Africa shows that as it will continue to experience increasing number and intensity of weather and climate extremes, including large increases in the frequency of heat extremes in West and Central Africa, increasing frequency of droughts in the south-west, and increased rainfall and the risk of flooding in Eastern Africa (IPCC, 2018).

In the case of Ethiopia, the National Meteorological Agency (NMA) (2001) revealed that climate variability and change are mainly manifested through the variability and a decreasing trend in rainfall and the increasing trend in temperature. Analysis of historical climate data indicates that the mean annual temperature of Ethiopia has increased by $1.3^{\circ} \mathrm{C}$ between 1960 and 2006, an average rate of 0.28 ${ }^{\circ} \mathrm{C}$ per decade. Moreover, they also noted that the increase in temperature in Ethiopia has been most rapid in June, August, and September at a rate of $0.32{ }^{\circ} \mathrm{C}$ per decade (McSweeney et al. 2008). Similarly, Agere (2017) noted an increase in both minimum and maximum temperatures in different local areas. This includes an increase in annual maximum temperature by $0.035,0.018$ and $0.095{ }^{\circ} \mathrm{C}$ for Mieso, Melkassa and Ademi Tulu, respectively and the same increasing trend of annual minimum temperature by $0.009,0.014$ and $0.018{ }^{\circ} \mathrm{C} /$ year for Mieso, Melkassa and Ademi Tulu respectively. However, climate projection made by IPCC (2007) for Ethiopia using historical data indicated that the mean annual temperature will increase in the range of $0.9-1.1^{\circ} \mathrm{C}$ by 2030 , in the range of $1.7-2.1{ }^{\circ} \mathrm{C}$ by 2050 and in the range of $2.7-3.4{ }^{\circ} \mathrm{C}$ by 2080 compared to $1961-1990$ normal.

With regards to rainfall, most climate change models over Ethiopia suggest little change or modest rainfall increases, although some models indicate increases and other reveals decreases in the quantity of rainfall (Senait et al. 2010; Fazzini et al. 2015; Amogne et al. 2018). In addition to this trend analysis computed using historical record of rainfall revealed different patterns of rainfall however majorities of studies showed couple of behaviors; decrease and variability in average rainfall in different parts of the country (Birhanu et al. 2017; Solomon et al. 2015; Prasada-Rao \& Solomon, 2014, Aklilu et al. 2014). Similarly, the National Adaptation Plan for Action (NAPA) (2007) stated that rainfall was highly variable and there is no clear trend in the amount of rainfall over time, based on the analysis result of historical rainfall records. On the other hand, according to IPCC (2007) rainfall remained more or less constant when averaged over the whole country while a declining trend has been observed over the Northern and Southwestern Ethiopia. Its impact is assumed as grave since most farmers have no access to irrigation when the rains do not come, farmers face substantial impacts, over 90 million populations is considered food insecure (Winthrop et al. 2018). Because, mostly farmers rely their living on rain fed agriculture were highly vulnerable to the impacts of climate change (Aggarwal et al. 2015) since agriculture is the most susceptible sector to climate change related hazards such as increase in temperature and both variability and decrease in rainfall (Solomon et al. 2015). Accordingly, Rao \& Solomon (2014) was concluded that climate change is a key emerging threat to the lives and livelihoods of the rural poor in Ethiopia.

Therefore, this call prompts policy makers to develop area-specific adaptation strategies besides of mitigation measures, to live with already changed and continually changing climate system. However, designing local area specific strategy needs context-based climate information but the challenge is to find long-term and/or continuous meteorological records in many parts of the developing world for analyzing local exposure to climate change (Riche et al. 2009). Because, understanding the characteristics of changes in temperature and distributions of rainfall in response to climate change is an important aspect of entire consideration of changes in heat extremes and their associated impacts on 
human and ecosystem health (Lewis and King, 2016). For this purpose, performing trend analysis using meteorological variables is important to determine the current climate change and creating a base for the future projections (Gumus et al. 2017). Because, the sustainability of economic development and living conditions depends on our ability to manage the risks associated with climate extreme events like drought and flood (WMO, 2009). Therefore, this study was aimed to produce area specific scientific information of climate in the geographic location of West Shoa zone using Mann-Kendall trend test. Accordingly, the study was tried to answer: (1) Variability analysis of monthly and seasonal rainfall; (2) Spatial distribution of monthly and seasonal rainfall; (3) Trend analysis of monthly and seasonal rainfall; (4) Trend analysis of monthly maximum temperature; (5) Trend analysis of seasonal and annual maximum temperature; (6) Trend analysis of monthly minimum temperature and (7) Trend analysis of seasonal and annual minimum temperature in West Shoa zone Oromia Regional State of Ethiopia.

\section{Methods}

2.1. Description of the study area

The study was conducted in West Shoa zone Oromia Regional State of Ethiopia, about $114 \mathrm{Km}$ from the capital city of the country, Addis Abeba. It is geographically located between $8^{\circ} 17^{\prime}$ and $9^{\circ} 56^{\prime} \mathrm{N}$ and $37^{\circ} 17^{\prime}$ and $38^{\circ} 45^{\prime} \mathrm{E}$. The site was purposively selected because it is the catchment area of Ambo University. West Shoa shares the boundaries on north with Amhara Regional state and North Shoa, on the East Addis Ababa region, on the west East Wollega and on the South west by south west Shoa and Jimma Zone. The total area of the zone is $15,086.15 \mathrm{~km}^{2}$. It is subdivided into 22 Woredas and two independent urban administrative zones namely Ambo and Holeta. Figure-1 below shows map of the research area.

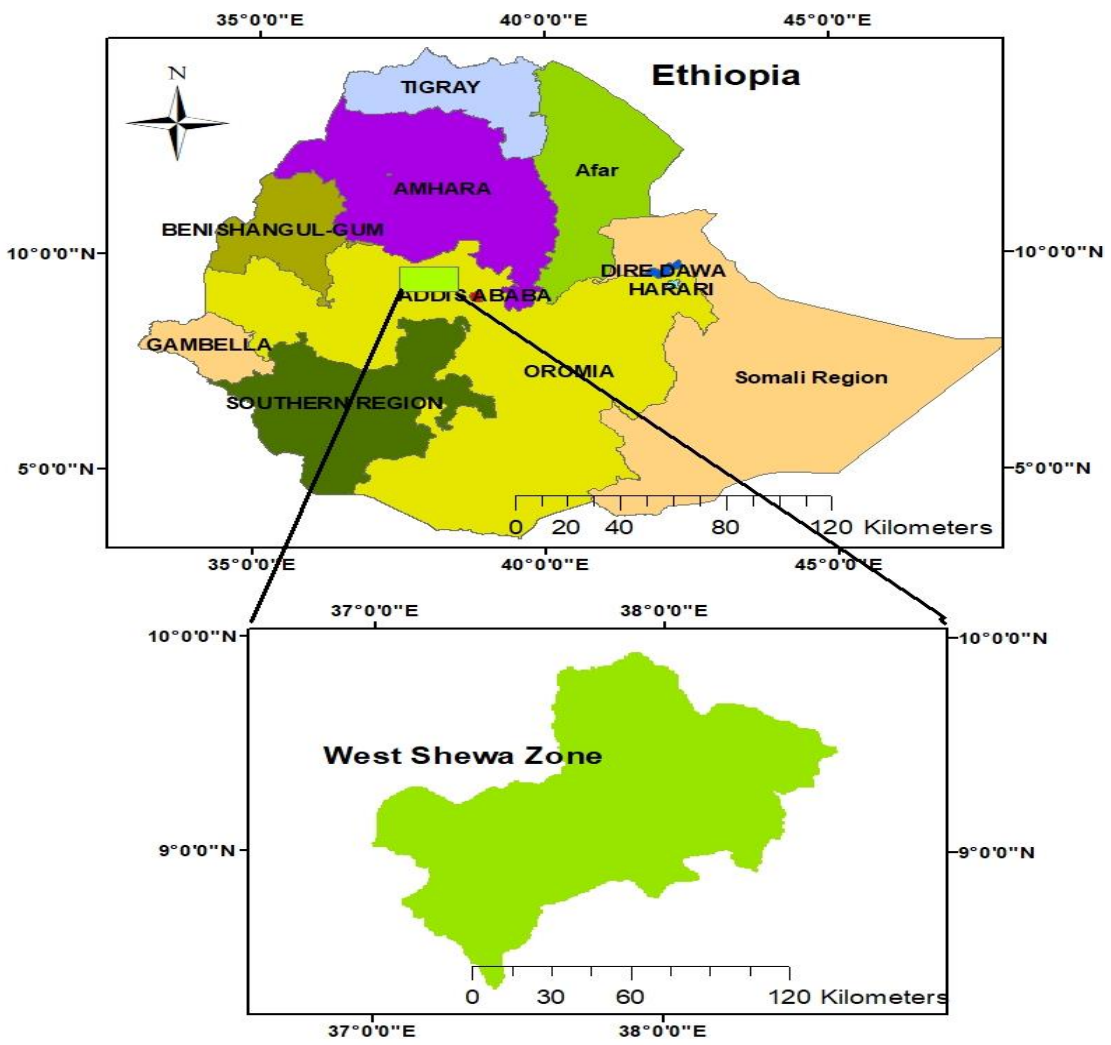

Figure 1: Map of the study area

\subsection{Data Types and Methods of Collection}

Daily rainfall, minimum and maximum temperature data of stations in the study area were obtained from National Meteorology Agency of Ethiopia. Among the existing meteorological stations in the zone, some stations have data only for rainfall and others are newly established having a few years' data for both rainfall and temperatures (table 1). As a result, stations that only have long periods of records were considered and the rest of the station which has records of few years was not included. Therefore, 16 stations (Addis Alem, Ambo Agriculture, Baco, Derba, Enchini, Fiche, Ginchi, Guder, Jeldu, Muke Turi, Nekemte, Shambu, Teji, Tibe, Tikur enchini and Tulu Bolo) for rainfall and 12 stations (Addis Alem, Ambo Agriculture, Baco, Derba, Fiche, Guder, Jeldu, Nekemte, Shambu, Tibe, Tikur enchini, and Tulu Bolo) for temperature data (1985-2015) were identified for variability and trend analysis in the study period. Of these Derba, Fiche, Muke Turi, Nekemte, Shambu, Teji, Tibe and Tulu Bolo are the stations 
included from the surrounding zones. The reason for collecting historical records of limited period was because in the national meteorology agency of Ethiopia the available record was only between 19852015.

Table 1 Selected gauge stations and synoptic stations in West Shoa and surrounding area

\begin{tabular}{|l|l|c|c|c|c|}
\hline S/N & Gage Stations & $\begin{array}{c}\text { Latitude }(\mathbf{N}) \text { in } \\
\text { degree }\end{array}$ & $\begin{array}{c}\text { Longitude }(\mathbf{E}) \text { in } \\
\text { degree }\end{array}$ & Class & Duration \\
\hline 1 & $\begin{array}{l}\text { Ambo } \\
\text { Agriculture }\end{array}$ & 8.98 & 37.83 & 1 & $1985-2015$ \\
\hline 2 & Addis Alem & 9.02 & 38.23 & 3 & $1985-2015$ \\
\hline 3 & Baco & 9.07 & 37.03 & 3 & $1985-2015$ \\
\hline 4 & Derba & 9.43 & 38.65 & 3 & $1985-2015$ \\
\hline 5 & Enchini & 9.32 & 38.37 & 4 & $1985-2015$ \\
\hline 6 & Fiche & 9.77 & 38.73 & 1 & $1985-2015$ \\
\hline 7 & Ginchi & 9.02 & 38.13 & 4 & $1985-2015$ \\
\hline 8 & Guder & 8.96 & 37.77 & 3 & $1985-2015$ \\
\hline 9 & Jeldu & 9.27 & 38.07 & 3 & $1985-2015$ \\
\hline 10 & Muke Turi & 9.55 & 38.87 & 4 & $1985-2015$ \\
\hline 11 & Nekemte & 9.09 & 36.54 & 1 & $1985-2015$ \\
\hline 12 & Shambu & 9.57 & 37.12 & 1 & $1985-2015$ \\
\hline 13 & Teji & 8.83 & 38.37 & 4 & $1985-2015$ \\
\hline 14 & Tibe & 9.05 & 37.17 & 3 & $1985-2015$ \\
\hline 15 & Tikur enchini & 8.82 & 37.65 & 3 & $1985-2015$ \\
\hline 16 & Tulu Bolo & 8.65 & 38.21 & 3 & $1985-2015$ \\
\hline
\end{tabular}

\subsection{Methods of data analysis}

As means of data analysis both descriptive and trend analysis was used. Descriptive statistical techniques such as minimum, maximum, mean (M), standard deviation (SD), coefficient of variation (CV), skewness, and kurtosis were computed to know the variability and distribution of climate data across the study area. Whereas, the Mann-Kendall trend test and Sen's slope were used to detect the time series trend of both rainfall and temperature and the magnitude of variation from the mean was analyzed respectively. For this, a statistical tool called XLSTAT2019 was used.

\subsection{Statistical tool for climate variability analysis}

The coefficient of variation (CV) is a statistical tool capable to understand how the individual data points vary about the mean value. A greater value of CV is the indicator of larger spatial variability, and vice versa. In this study, the analysis conducted to detect the variation of monthly, seasonal and annual rainfall and temperature data of meteorology records of 16 stations found in West Shoa zone and surrounding zones CV were used as a statistical tool. This CV has been widely used by many scholars for the analysis of climatologic data (Landsea and Gray; 1992, Issahaku et al. 2016; Martha \& Negeswara, 2016; Hadju et al. 2013).

\subsection{Mann-Kendall test for trend analysis (Non-parametric)}

The Mann-Kendall (MK) test is used to detect monotonically (increasing or decreasing) trends and is widely used for detecting trends in time series analysis because it is simple, robust, accommodate missing values (Yu et al. 1993; Douglas et al. 2000; Yue et al. 2003; Burn et al. 2004, Singh et al. 2008). In meteorological records the appearance of outliers are common; however, the non-parametric Mann Kendall test is capable to fix this problem because its statistic is based on the (+ or -) signs, rather than the values of the random variable, and therefore, the trends determined are less affected by the outliers (Helsel and Hirsch, 1992; Birsan et al. 2005).

The Mann-Kendall statistic $S$ of the series $\mathrm{x}$ is given by test (Mann, 1945; Kendall, 1975):

$$
\mathrm{S}=\sum_{i-1}^{n-1} \quad \sum_{i-1}^{n-1} \operatorname{sgn}(\mathrm{xj}-\mathrm{xi}) .
$$

Where $X j$ and $X i$ are the annual values in years $j$ and $i, j>i$, respectively, and

$$
\operatorname{sgn}(x j-x i)=\left\{\begin{array}{c}
1 \text { if } x j-x i>0 \\
0 \text { if } x j-x i=0 \\
-1 \text { if } x j-x i<0
\end{array}\right.
$$

A positive value of $S$ connotes and "upward trend or increasing trends", while a negative value of $S$ indicates a "downward trend or decreasing trends". 
It is necessary to compute the probability associated with $\mathrm{S}$ and the sample size, $\mathrm{n}$, to statistically quantify the significance of the trend. The variance associated with $\mathbf{S}$ is calculated from (Mann 1945; Kendall, 1975):

$$
\operatorname{Var}(S) \operatorname{Var}(S)=\frac{n(n-1)(2 n+5)-\sum_{k=1}^{m} t k(t k-1(2 t k+5)}{18} .
$$

Where $\mathrm{m}$ is the number of tied groups and $t_{k}$ is the number of data points in group $\mathrm{k}$. In cases where the sample size $\mathrm{n}>10$, the test statistic Z(S) is calculated from (Mann 1945, Kendall 1975):

$$
\begin{aligned}
& \mathrm{Z}=\frac{S-1}{\sqrt{\operatorname{var}(s)}} \text { if } \mathrm{S}>0, \mathrm{Z}=0 \text { if } \mathrm{S}=0 \text {. } \\
& \mathrm{Z}=\frac{S-1}{\sqrt{\operatorname{var}(s)}} \text { if } \mathrm{S}<0 \text {. }
\end{aligned}
$$

The trend is said to be decreasing if $Z$ is negative and the absolute value is greater than the level of significance, while it is increasing if $Z$ is positive and greater than the level of significance. If the absolute value of $Z$ is less than the level of significance, there is no trend. In this study the desired value of $a$ is 0.05; that indicates the level of confidence (Birhan, 2017).

\subsection{The Sen's slope estimator}

Sen's slope is an alternative, more robust, a nonparametric estimate of the slope of time series. In the nonparametric statistical tool, the magnitude of a trend exists in the time series was estimated by a slope estimator B (Hirsch et al. 1982). B is the robust estimate of the trend magnitude. In other words, the slope estimator $B$ is the median over all possible combinations of pairs for the whole data set. A positive value of $B$ indicates an 'upward trend' (increasing values with time), while a negative value of $B$ indicates a 'downward trend' (Xu et al. 2007, Karpouzos et al. 2010). During the computation of Sen's slope, all sets of slopes (dk) are calculated using each pair of Xi and Xj using Equation (5). Then, the Sen Slope (B1) is calculated as the median of all slopes, dk, using Equation (6) (Pohlert, 2018). Each set of slopes (dk) is calculated by

$$
\mathrm{dk}=\frac{x j-x i}{j-i}
$$

The Sen Slope (B1) is calculated by

$$
\mathrm{B} 1=\text { median }(\mathrm{dk})=\text { median }=\left(\frac{x j-x i}{j-i}\right)
$$

Where $i$ and $j$ are indices for values of the variable $X$, for all $1_{-} i<j \_n$.

\section{Results and discussion}

\subsection{Variability analysis of monthly and seasonal rainfall}

Analysis of variability and trends of main parameters of climate, rainfall and temperature, either on a monthly or seasonal as well as annual basis has high importance to inform policy and decision-makers trying to design a strategy either to adapt or mitigate the adverse impacts of climate change in the community. Table 2 shows the results of the descriptive analysis of both monthly and seasonal rainfall of the study area for the period of 1985-2015. The mean annual rainfall of the area from 1985-2015 was $1355.08 \mathrm{~mm}$ with standard deviation (SD) of 146.70 and $10.8 \%$ of the CV. The minimum and maximum records of rainfall were $1128.93 \mathrm{~mm}$ and $1876.70 \mathrm{~mm}$ respectively. As portrayed in table 2, summer (locally known as Kiremt rain) was found to be the season when high amounts of rain $(M=763.21 \mathrm{~mm})$ was received with relatively low variation $(\mathrm{CV}=10.1 \%)$. And it was also the main rainy season (June, July, and August) that has a significant contribution to the total amounts of rainfall received on an annual basis $(M=1355.08 \mathrm{~mm})$. The second-highest amount of mean rainfall $(263.07)$ was received during the spring season, locally known as Belg rain (March-May). It was a short rainy season when the area gets an important rain for their livelihood with moderate levels of variability, $28.5 \%$ of the CV. Contrary to this, winter (locally known as Bega rain, December-February), was the season with least amounts of rain $(M=79.75 \mathrm{~mm})$ recorded, and the rain at this time was not as such demanded as compared to summer and spring season. This study is in line with the findings of Koricha et al. (2012) \& Girma et al. (2015) who reported that summer is the main season contributing the highest to the annual rainfall received in different parts of the country.

Regarding variability, low to very high levels of variability were recorded in the seasonal for annual rainfall whereas and moderate to extremely high levels of variability were observed for the coefficient of variation in monthly rainfall. Because, coefficient of variation (CV) is the tool of descriptive statistics widely used to classify the degree of variability as less $(\mathrm{CV}<20 \%)$, moderate $(20<\mathrm{CV}<30 \%)$, high $(\mathrm{CV}>30 \%)$, very high $(C V>40 \%)$ and extremely high $(C V>70 \%)$ (Hare, 2003). Accordingly, July was the month with low levels of variability, $11.1 \%$ of CV and December was the month showed extreme levels of variability, $96.1 \%$ of the CV. Among seasons summer was the season with less coefficient of variation $(10.1 \%)$ while winter was the season with the highest coefficient of variation were recorded $(37.12 \%)$ in the area. This 
implies that the pattern of rainfall was comparatively stable during the main sowing season as compared to other seasons. Brihan (2018) found that the rainfall pattern in the Kiremt season was less variable than the rain in the Belg season (March to May) in the south Gonder zone of Amhara regional state of Ethiopia. Just as the summer season annual rainfall also showed less annual and inter-annual variability in the study area, $10.8 \%$ of the CV. This is in agreement with the output of Woldeamlak and Conway (2007), who stated that rainfall shows moderate inter-annual variability in drought-prone areas of Amhara regional state of Ethiopia. The present study is disagreeing with the finding of Asaminew \& Diriba (2015) conducted in the Northern Oromia zone and conducted in the Tigray regional state of Ethiopia (Gebre et al. 2013). Both researchers concluded that the presence of high inter-annual variability of rainfall in their specific study area. In contrast, the finding is in agreement with Solomon et al. (2017) indicated that the annual and seasonal rainfall totals showed that the area has moderate to high variable rainfall conditions.

Table 2: Descriptive statistics of monthly and seasonal rainfall data in $\mathrm{mm}$ from 1985-2015

\begin{tabular}{|l|c|c|c|c|c|c|c|}
\hline Variable & Minimum & Maximum & Mean & SD & CV (\%) & Skewness & Kurtosis \\
\hline January & 3.13 & 52.29 & 22.72 & 14.03 & 61.8 & 0.62 & -0.57 \\
\hline February & 8.85 & 100.95 & 37.67 & 24.45 & 64.9 & 0.86 & 0.12 \\
\hline March & 10.55 & 166.39 & 65.70 & 37.13 & 56.5 & 0.66 & 0.13 \\
\hline April & 34.54 & 200.48 & 87.25 & 34.59 & 39.6 & 1.12 & 2.18 \\
\hline May & 19.53 & 194.98 & 110.12 & 45.59 & 41.4 & -0.04 & -0.92 \\
\hline June & 146.93 & 279.87 & 199.92 & 30.10 & 15.1 & 0.46 & 0.72 \\
\hline July & 221.33 & 354.42 & 285.10 & 31.62 & 11.1 & -0.19 & -0.11 \\
\hline August & 221.87 & 384.59 & 278.19 & 37.19 & 13.4 & 0.73 & 0.71 \\
\hline September & 101.99 & 237.92 & 165.92 & 29.53 & 17.8 & 0.10 & 0.29 \\
\hline October & 12.85 & 132.59 & 56.89 & 37.72 & 66.3 & 0.66 & -0.87 \\
\hline November & 2.93 & 76.17 & 26.50 & 21.75 & 82.1 & 1.17 & 0.16 \\
\hline December & 0.71 & 67.29 & 19.11 & 18.36 & 96.1 & 1.41 & 0.96 \\
\hline Spring & 145.51 & 434.28 & 263.07 & 75.02 & 28.5 & 0.46 & -0.42 \\
\hline Summer & 621.73 & 1018.88 & 763.21 & 76.75 & 10.1 & 1.18 & 2.58 \\
\hline Autumn & 132.42 & 387.20 & 249.31 & 59.74 & 24.0 & 0.54 & -0.08 \\
\hline Winter & 16.19 & 174.60 & 79.75 & 37.12 & 46.5 & 0.68 & 0.14 \\
\hline Annual & 1128.93 & 1876.70 & 1355.08 & 146.70 & 10.8 & 1.53 & 3.93 \\
\hline
\end{tabular}

\subsection{Spatial distribution of monthly and seasonal rainfall}

Distribution of rainfall was analyzed using both descriptive statistical methods (normality test and normal distribution methods) and Box plot figures. In table 3, a normality test computed using the Shapiro-Wilk test and Anderson-Darling test shows that the patterns of annual rainfall distribution were irregular and was significant at alpha $=0.05$. Similarly, patterns of the main rainy season, summer specifies the irregular distribution of rainfall with the Shapiro-Wilk test but it showed normal distribution with the Anderson-Darling test. In contrast, the spring, autumn, and winter seasons rainfall showed a relatively normal distribution in both cases of normality test because the levels of significances are greater than alpha $=0.05$ in all cases. This indicates that the patterns of rainfall were not normally distributed during the main planting season, summer, but it was comparatively normal in unwanted periods of the season. Such irregularity in the sowing period was among the challenge of farmers of the study area in particular and the country in general.

Concerning the pattern of rainfall with normal distribution, both the summer and annual rainfall highlighted positively skewed distribution but moderately skewed distribution was observed during spring, autumn and winter seasons (Table 2). In all months and seasons, the distribution of rainfall showed platykurtic (Kurtosis<3) shape with thinner tails as compared to the normal distribution (Kurtosis=3). From this, we can conclude that there were no significant amounts of outliers in the data set of seasonal rainfall, and possible to say the distribution of the rainfall was relatively normal. In contrast, the annual rainfall showed Leptokurtic (Kurtosis>3) distribution, which means the data are tailed (Table 2). This implies the existence of excess amounts of outliers in the data set of annual rainfall as compared to both monthly and seasonal rainfall.

On the other hand, a monthly distribution of rainfall showed from positively-skewed to fairly symmetrical distribution patterns of rainfall in the data set. In this regard, three months (April, November, and December) showed positively skewed, five months (January, February, March, August, and October) were revealed moderately skewed and four months (May, June, July, and September) found to be a fairly symmetrical distribution of rainfall in the study area. Besides, all 12 months showed a platykurtic distribution of rainfall in the study area. In other words, the distribution of rainfall was not 
showed any outlier or extreme data as compared to mesokurtic distribution. However, any amount of deviation in rainfall from normal distribution either on a monthly or seasonal scale has a non-ignorable influence on the agricultural activities of the area. A small change in amount and distribution of main season (June to September) rainfall could negatively influence crop production which is already impacted by the current climate variability (Girma et al. 2015). Similarly, different reports also concur with the present findings (Lupi and Kibert, 2019; NAPA, 2007; NMA, 1996). Irregularity and deficiency in the main rain season have a serious effect on the food production of Ethiopia.

Table 3: Normality tests of seasonal rainfall data from 1985-2015

\begin{tabular}{|l|c|c|c|c|}
\hline \multirow{2}{*}{ Variable/Test } & \multicolumn{2}{|c|}{ Shapiro-Wilk test } & \multicolumn{2}{c|}{ Anderson-Darling test } \\
\cline { 2 - 5 } & W & P-value & A $^{2}$ & p-value \\
\hline Spring & 0.96 & 0.401 & 0.32 & 0.512 \\
\hline Summer & 0.92 & $\mathbf{0 . 0 3 1}$ & 0.66 & 0.078 \\
\hline Autumn & 0.96 & 0.374 & 0.40 & 0.344 \\
\hline Winter & 0.95 & 0.198 & 0.55 & 0.143 \\
\hline Annual & 0.85 & $\mathbf{0 . 0 0 1}$ & 1.40 & 0.001 \\
\hline
\end{tabular}

In addition, to better understand the statistical distribution of the wide data set of rainfall, the compact nature of the graphical plot was generated using XLSTAT and it showed in the below figure 1. Tukey (1977) the compact nature of box and whisker plots help the assessment of multiple datasets, which can otherwise be difficult to interpret using more complete representations, such as the histogram form of graphical representation (Banacos, 2011). The box and whisker plots graphically describe the statistical distribution in a way that is easy to understand for a wide range of users. The form of the box and whisker plot here include a central horizontal line representing the median and the inter-quartile range's top and bottom of the horizontal lines (shown by the box). The bottom and top horizontal lines in the boxes indicate the $25^{\text {th }}$ and $75^{\text {th }}$ percentiles, respectively. The outer ranges are drawn as vertical lines called whiskers, still showing the distribution of the data set.

Here, the location of the median line suggests skewness in the distribution if it is markedly shifted away from the center. The length of the interquartile range as shown by the box is a measure of the relative dispersion of the middle $50 \%$ of a dataset, just as the length of each whisker is a measure of the relative dispersion of the dataset's outer range $\left(10^{\text {th }}\right.$ to $25^{\text {th }}$ percentiles and $75^{\text {th }}$ to $90^{\text {th }}$ percentiles) (Banacos, 2011). The below figure 2 presents the box plots of the seasonal and annual rainfalls observed at 16 stations that found in West Shoa zone and surrounding zones for the periods of 1985-2015. Consequently, the box plots produced for the summer season and annual rain showed the existence of positively skewed distribution or positive skew with outliers in both sides of the box however the position of outliers representing point is somewhat away from the end of whiskers in the case of annual rainfall as compared to summer, representing the presence of many outliers in annual rainfall. On the other hand, the plus sign is above the center horizontal line (median point) representing the presence of relatively large amounts of data on the positive side of the box.

Similarly, positively skewed distribution or positive skew were observed during winter and spring rainfall however the interpretation of the box plots could be different in both cases. In the case of the box plot of winter season though the box at bottom of the median line is wider the whisker is relatively longer in the upper side and the plus sign is laid above the median line. In contrast, during spring season the box above the median line is wider and the whisker is longer on one side, upper side (representing the concentration of rainfall data higher in the positive side) showing a positive trend. In addition, though there was no point that representing the presence of outliers in the downside of the whisker in the case of winter season box plot but there is the point of outliers in the upper side of the ends of the whisker as compared to no such sign in both sides of the spring season. That exhibits the presence of no extreme rainfall during the spring season and showing the reality of extreme rainfall in the area during the winter season. On the other hand, symmetrical distribution was observed during the autumn season because of the appearance of the central horizontal line that representing the median and equal length of the whiskers on both sides of the box.

The pattern of rainfall in the study area not only limited to the various levels of variability and deviation from normal distribution but also showed ups and downs in the trends. Accordingly, the total annual, summer and autumn rainfall exhibits increasing trend while the spring and winter season rainfall showed decreasing trends; however, it was not statistically significant. The result of this study is in convergence with the finding of $4^{\text {th }}$ AR of IPCC (2007), which argues that the projected $\left(21^{\text {st }}\right.$ century) mean annual rainfall trend is likely to be increasing in East Africa. Similarly, Tefera and Agena (2016) 
reported the reality of both the increasing and decreasing trends of rainfall in the Gamo Gofa zone in southwestern Ethiopia. In agreement with the present study, Daniel et al. (2014) noted that the annual total rainfall has shown an increasing trend of $35 \mathrm{~mm}$ per decade; however, it was not statistically significant over the Upper Blue Nile River Basin of Ethiopia. In contrast, the finding of Negash et al. (2013) is in opposition to the present study. In their study, they reported that the existence of decreasing the trend in annual rainfall over the northern, northwestern, and western parts of Ethiopia. In addition, the present study disagrees with the findings of Hailu et al. (2018) which showed decreasing trends of annual rainfall in the Tana Basin region and the same decreasing trend was observed in Tigray North Ethiopia (Gebre, 2013).
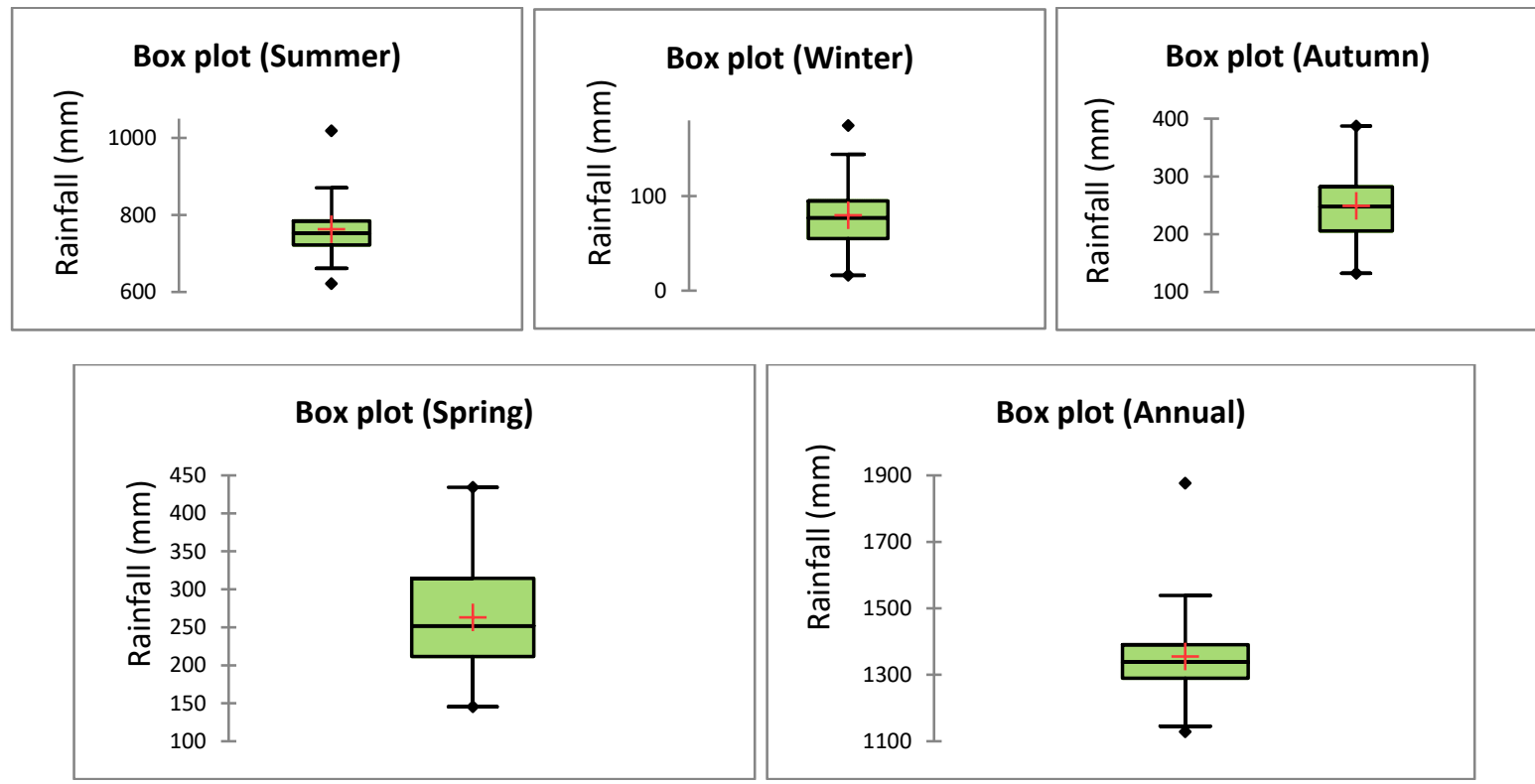

Figure 2: Box plot showing the variability of seasonal rainfall over the study areas for the period 19852015

\subsection{Trend analysis of monthly and seasonal rainfall}

Table 4 depicts the result of a trend analysis of monthly and seasonal rainfall patterns in the study area. Accordingly, the pattern of rainfall was increasing with the majority of months except in February, March, April, and August, it showed a decreasing trend in the study area. However, the pattern of increasing trends of rainfall was statistically significant in November at alpha $=0.05$ while it showed decreasing trends in February that is also statistically significant at alpha $=0.05$. On the other hand, in the spring and winter season, the rainfall showed a decreasing trend by $-0.09 \mathrm{~mm}$ and $-0.80 \mathrm{~mm}$ of Sen's slope respectively. Surprisingly, though the result of the MK test exhibits positive trends during the summer season in figure 3 below the slope line shows the presence of a negative trend in the patterns of rainfall under the given period of time series. Here, the probable suggestion is that even if it shows positive with MK test but there could be a decreasing trend and that was not easy to depict with descriptive analysis; however, is relatively easy to stick out with graphic representation. This is maybe also the advantage of graphic representation of the result as compared to statistical tools. In general, the annual rainfall shows an increasing trend with the MK test of 0.09 and by $1.29 \mathrm{~mm}$ with Sen's slope, however, it was not statistically significant. This is in agreement with studies conducted in Gurage Zone by Solomon et al. (2017). They noted that the trends of rainfall were decreasing in Belg and increasing both in annual and Kiremt season, but the trends were non-significant. 
Table 4: Trend analysis of monthly and seasonal rainfall data from 1985-2015

\begin{tabular}{|l|c|c|c|}
\hline Series\Test & MK test & p-value & Sen's slope \\
\hline January & 0.07 & 0.592 & 0.17 \\
\hline February & -0.26 & 0.046 & -1.14 \\
\hline March & -0.11 & 0.392 & -0.76 \\
\hline April & -0.09 & 0.475 & -0.61 \\
\hline May & 0.17 & 0.187 & 1.63 \\
\hline June & 0.15 & 0.239 & 0.78 \\
\hline July & 0.02 & 1.000 & 0.10 \\
\hline August & -0.15 & 0.254 & -1.04 \\
\hline September & 0.02 & 0.915 & 0.11 \\
\hline October & 0.06 & 0.669 & 0.49 \\
\hline November & 0.30 & 0.020 & 0.77 \\
\hline December & 0.18 & 0.175 & 0.37 \\
\hline Spring & -0.02 & 1.000 & -0.09 \\
\hline Summer & 0.02 & 0.887 & 0.20 \\
\hline Autumn & 0.21 & 0.116 & 1.69 \\
\hline Winter & -0.10 & 0.432 & -0.80 \\
\hline Annual & 0.09 & 0.521 & 1.29 \\
\hline
\end{tabular}
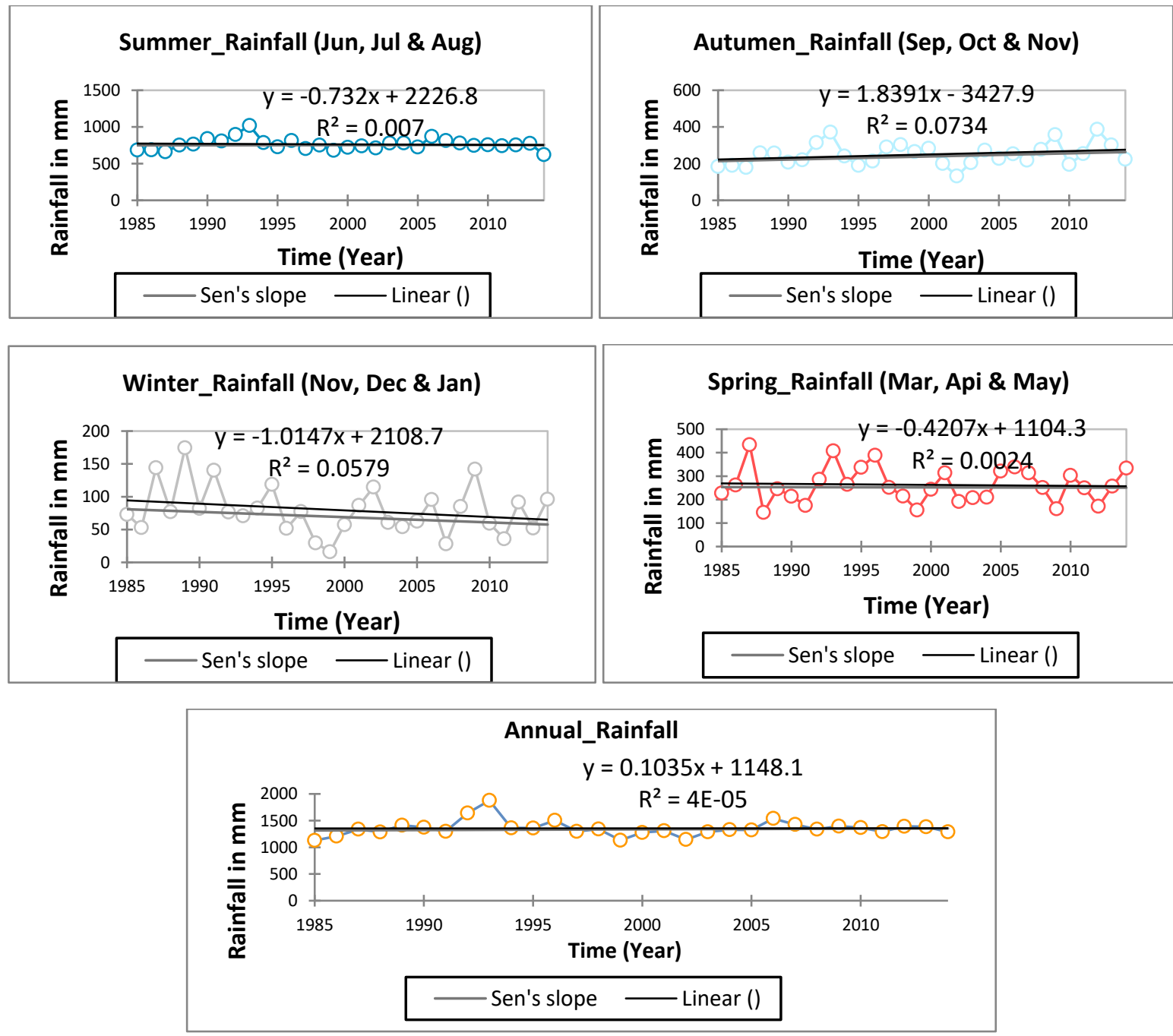

Figure 3: Seasonal trends of rainfall in the study area from 1985-2015 


\subsection{Trend analysis of monthly maximum temperature}

Surface air temperature is one of the most important elements in weather and climate forecasting, so examination of its behavior is important for understanding climate variability which can vary spatially and temporally at different local, regional and global scales (Ghasemi, 2015). On the other hand, the temperature is the key factor that has the ability to influence other elements of the atmosphere. In view of that, the mean monthly and seasonal minimum and maximum temperature for the periods of 1985-2015 was computed using descriptive statistics (such as mean, SD, CV, Skewness, and Kurtosis) and trend with time series analysis tools of the Mann Kendall (MK) test and Sen's slope.

Table 5 shows the result of the maximum temperature of the West Shoa zone. Accordingly, August was the month when the lowest mean of maximum temperature was recorded $\left(22.05{ }^{\circ} \mathrm{C}\right)$ but not an insignificant manner. In contrast, March was the month with the highest mean $\left(26.49{ }^{\circ} \mathrm{C}\right)$ of maximum temperature that was statistically significant at alpha $=0.01$. Here, the analysis of the MK test shows an increasing trend in all months except in November and December but not statistically significant. Moreover, the slope of linear regression model in figure 3 below portrays the change in the mean maximum temperature of the area was by the rate of $0.0315{ }^{\circ} \mathrm{C} / 30$ years. The study is in agreement with Amogne et al. (2018) stated that monthly maximum temperature showed an increasing trend (except in April and November) in the central parts of Ethiopia. Regards variability, the mean maximum temperature showed less variation in all months $(2.38 \%$ to $4.18 \%)$ of CV. Similarly, in all the months the magnitude of trends showed relatively very low magnitude with Sen's slope while November and December specified a negative magnitude in the study area.

As far as understanding the patterns of temperature was a crucial computing the distribution of temperature was checked through analysis of skewness and kurtosis. Accordingly, the distribution of mean maximum temperature was fairly symmetrical in majorities of months except in October, when it showed negatively skewed distribution with no records of outliers. This implies that the pattern of mean maximum temperature was moved in the normal distribution mood with no sign of high extreme events than steadily increasing. Similar patterns of an increasing trend with mean annual maximum temperature observed in different parts of Ethiopia have been reported by other researchers (Hailu et al. 2018; Miseker et al. 2017; Tefera and Agena, 2016; Solomon et al. 2015; Birhan, 2018).

Table 5: Descriptive statistics and MK trend analysis of mean monthly maximum temperature from 1985-

\begin{tabular}{|l|c|c|c|c|c|c|c|c|}
\hline Statistic & Mean & SD & CV (\%) & MK test & $\begin{array}{c}\text { p- } \\
\text { value }\end{array}$ & $\begin{array}{c}\text { Sen's } \\
\text { slope }\end{array}$ & Skewness & Kurtosis \\
\hline January & 25.56 & 0.93 & 3.63 & 0.15 & 0.239 & 0.03 & -0.22 & -0.44 \\
\hline February & 26.19 & 0.85 & 3.25 & 0.49 & $\mathbf{0 . 0 0 0}$ & 0.06 & -0.20 & -0.16 \\
\hline March & 26.49 & 1.11 & 4.18 & 0.42 & $\mathbf{0 . 0 0 1}$ & 0.07 & 0.16 & -0.66 \\
\hline April & 26.18 & 0.98 & 3.74 & 0.54 & $\mathbf{0 . 0 0 0 1}$ & 0.08 & -0.28 & -0.70 \\
\hline May & 25.71 & 0.97 & 3.77 & 0.31 & $\mathbf{0 . 0 1 7}$ & 0.05 & 0.34 & -0.37 \\
\hline June & 24.08 & 0.80 & 3.32 & 0.30 & $\mathbf{0 . 0 2 0}$ & 0.04 & 0.41 & 0.28 \\
\hline July & 22.22 & 0.77 & 3.45 & 0.11 & 0.392 & 0.02 & -0.23 & -0.73 \\
\hline August & 22.05 & 0.76 & 3.43 & 0.06 & 0.669 & 0.01 & 0.12 & -1.07 \\
\hline September & 22.99 & 0.60 & 2.60 & 0.15 & 0.254 & 0.02 & 0.21 & -0.69 \\
\hline October & 24.17 & 0.68 & 2.80 & 0.18 & 0.164 & 0.02 & -0.73 & -0.40 \\
\hline November & 24.69 & 0.66 & 2.66 & -0.07 & 0.617 & -0.01 & -0.12 & -0.72 \\
\hline December & 24.93 & 0.60 & 2.38 & -0.05 & 0.695 & -0.01 & -0.12 & -0.60 \\
\hline
\end{tabular}




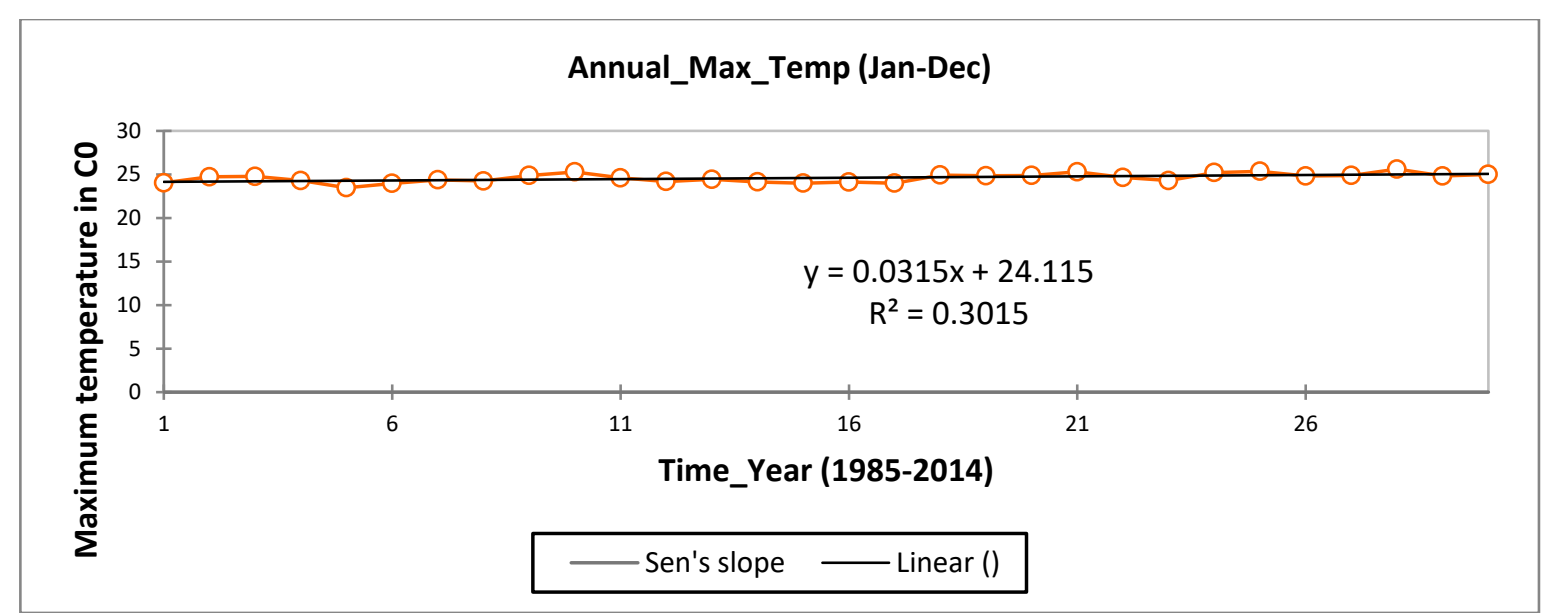

Figure 4: Trend analysis annual mean maximum temperature from 1985-2015

\subsection{Trend analysis of seasonal and annual maximum temperature}

The below table 6 shows the basic statistical and trend analysis of seasonal and annual mean maximum temperature of the area within the time serious of 1985-2015. Accordingly, summer was the period when the lowest mean of maximum temperature was recorded $\left(22.78{ }^{\circ} \mathrm{C}\right)$ while spring was the season when the highest maximum temperature was recorded $\left(26.13^{\circ} \mathrm{C}\right)$. Hence, a statistically warming trend was observed in the mean annual and seasonal maximum temperature of the area however it was not statistically significant during summer and autumn. The observed variability of the mean maximum temperature of the area was less with the coefficient of variation, below $20 \%$. Among the seasons highest, $0.07{ }^{\circ} \mathrm{C}$ of temperature was recorded in spring while the lowest, $0.01{ }^{\circ} \mathrm{C}$ of temperature was observed during the winter season. Regarding distribution autumn and annual maximum temperature were indicated negatively skewed, while spring, summer, and winter were found to be a fairly symmetrical distribution of mean maximum temperature under the course of the study period. On the other hand, the shape of distribution was appeared as platykurtic, represents there were no observable extreme events that occurred under the course of study periods.

Table 6: Descriptive statistics and MK trend analysis of mean maximum temperature in seasonal scale from 1985-2015

\begin{tabular}{|l|c|c|c|c|c|c|c|c|}
\hline Statistic & Mean & SD & CV (\%) & MK test & p-value & $\begin{array}{c}\text { Sen's } \\
\text { slope }\end{array}$ & Skewness & Kurtosis \\
\hline Spring & 26.13 & 0.84 & 3.22 & 0.52 & $\mathbf{0 . 0 0 0 1}$ & 0.07 & -0.01 & -0.23 \\
\hline Summer & 22.78 & 0.68 & 2.99 & 0.18 & 0.164 & 0.02 & 0.02 & -0.87 \\
\hline Autumn & 23.95 & 0.53 & 2.20 & 0.11 & 0.412 & 0.01 & -0.51 & -0.66 \\
\hline Winter & 25.90 & 0.76 & 2.93 & 0.28 & $\mathbf{0 . 0 3 0}$ & 0.04 & -0.05 & -0.23 \\
\hline Annual & 24.60 & 0.51 & 2.06 & 0.37 & $\mathbf{0 . 0 0 4}$ & 0.03 & -0.07 & -0.58 \\
\hline
\end{tabular}

\subsection{Trend analysis of monthly minimum temperature}

Table 7 below depicts the statistical result of the mean monthly analysis of the minimum temperature of the study area within the time series of 1985-2015. A statistically significant increasing trend was observed with a mean monthly minimum temperature of the area except in February and December, it showed an insignificant trend. April was the month when the highest mean minimum temperature was recorded $\left(11.12{ }^{\circ} \mathrm{C}\right)$ while December was the month when the lowest mean minimum temperature $(8.42$ ${ }^{\circ} \mathrm{C}$ ) was recorded within the time series. Regards the variability of the mean minimum temperature of the area all the months lay between the ranges of $5.81 \%$ to $11.33 \%$ of $\mathrm{CV}$, the lowest variation. However, the relatively highest rate of increase in temperature was by $0.07^{\circ} \mathrm{C}$ of Sen's slope was recorded May and the same lowest magnitudes of trends $\left(0.03{ }^{\circ} \mathrm{C}\right)$ were recorded during three months such as February, October, and December. In addition, the below figure 5 indicates the pattern of increasing trends of mean minimum temperature in the rates of $0.0469^{\circ} \mathrm{C} / 30$ years. This is below the national mean annual minimum temperature that reported as it was increased by about $0.37^{\circ} \mathrm{C}$ every ten years over the past 55 years (1951-2006) (NMA, 2007). Similarly, Solomon et al. (2015) found that monthly minimum temperature showed a significant increasing trend in Lake Tana Sub-basin, Ethiopia. From this, it is possible to conclude that the rates of increase in mean temperature were relatively higher with minimum temperature than maximum. Human Development Right (HDR) (2007/8) also noted that the annual time series of minimum and maximum temperature for 40 stations averaged over Ethiopia reveals a warming trend in temperature and it is evident that the average annual minimum temperature is increasing much faster than the average annual maximum temperature as noted by (Belay et al. 2013). 
Concerning distribution, the mean minimum temperature of the study area was showed negatively symmetrical during February, May, October, and December while the rest of the months were revealed fairly symmetrical distribution. In addition, during the courses of the study year the distribution of mean minimum temperature was showed platykurtic, no significant amounts of extreme temperature were recorded in the study area. This was also similar to the dispersion patterns of maximum temperature in the study area.

Table 7: Descriptive statistics and MK trend analysis of monthly minimum temperature from 1985-2015

\begin{tabular}{|l|c|c|c|c|c|c|c|c|}
\hline Statistic & Mean & SD & CV (\%) & MK test & $\begin{array}{c}\text { p- } \\
\text { value }\end{array}$ & $\begin{array}{c}\text { Sen's } \\
\text { slope }\end{array}$ & $\begin{array}{c}\text { Skewnes } \\
\text { s }\end{array}$ & Kurtosis \\
\hline January & 9.08 & 0.78 & 8.60 & 0.43 & $\mathbf{0 . 0 0 1}$ & 0.05 & -0.49 & 1.78 \\
\hline February & 9.97 & 0.89 & 8.88 & 0.21 & 0.101 & 0.03 & -0.52 & 0.15 \\
\hline March & 10.78 & 0.75 & 6.99 & 0.49 & $\mathbf{0 . 0 0 0}$ & 0.05 & -0.47 & 0.36 \\
\hline April & 11.12 & 0.82 & 7.35 & 0.44 & $\mathbf{0 . 0 0 1}$ & 0.06 & -0.41 & -0.44 \\
\hline May & 11.09 & 0.97 & 8.79 & 0.53 & $\mathbf{0 . 0 0 0 1}$ & 0.07 & -0.65 & 0.40 \\
\hline June & 10.82 & 0.63 & 5.81 & 0.54 & $\mathbf{0 . 0 0 0 1}$ & 0.05 & -0.23 & -0.58 \\
\hline July & 10.87 & 0.61 & 5.59 & 0.52 & $\mathbf{0 . 0 0 0 1}$ & 0.05 & -0.28 & -0.41 \\
\hline August & 10.66 & 0.65 & 6.07 & 0.38 & $\mathbf{0 . 0 0 3}$ & 0.04 & -0.44 & -0.05 \\
\hline September & 10.08 & 0.63 & 6.21 & 0.42 & $\mathbf{0 . 0 0 1}$ & 0.04 & 0.22 & -0.50 \\
\hline October & 9.17 & 0.65 & 7.07 & 0.29 & $\mathbf{0 . 0 2 5}$ & 0.03 & -0.54 & -0.08 \\
\hline November & 8.55 & 0.79 & 9.27 & 0.43 & $\mathbf{0 . 0 0 1}$ & 0.05 & 0.47 & 0.97 \\
\hline December & 8.42 & 0.95 & 11.33 & 0.12 & 0.372 & 0.03 & -0.08 & -0.93 \\
\hline
\end{tabular}

\subsection{Trend analysis of seasonal and annual minimum temperature}

The mean annual minimum temperature of the area was $10.05^{\circ} \mathrm{C}$ with lowest mean records in autumn $\left(9.27^{\circ} \mathrm{C}\right)$ and highest in spring $\left(10.99{ }^{\circ} \mathrm{C}\right)$ seasons (table 8). The result also indicates that the trend of mean seasonal and annual temperature of the area shows statistically significant trends at 0.01 levels of significance. Concerning the variability of mean minimum temperature, it was low in all seasons including the annual temperature. Moreover, the result reveals that the highest increase in mean minimum temperature was observed during spring $\left(0.06^{\circ} \mathrm{C}\right)$ in contrast, the slowest increase in mean minimum temperature was observed during the winter season $\left(0.03^{\circ} \mathrm{C}\right)$ with Sen's slope test.

Generally, the average rate of increase in both minimum and maximum temperature of the area lays between $0.0485{ }^{\circ} \mathrm{C} / 30$ years and $0.0315{ }^{\circ} \mathrm{C} / 30$ years, respectively, is below the global average rate which was 0.85 [0.65 to 1.06 ] ${ }^{\circ} \mathrm{C}$ over the period of 1880 to 2012 (IPCC, 2014). Similarly, it was also below the mean annual temperature of Ethiopia that increased by $1.3^{\circ} \mathrm{C}$ between 1960 and 2006 , at an average rate of $0.28^{\circ} \mathrm{C}$ per decade (McSweeney et al. 2008). However, it was low as compared to both the global and country rate though there was variation in the periods of studies. But it is not to mean low on the local scale by considering the consequent impacts because it has many implications on water availability and crop production where rain-fed agriculture is the mainstay of farmers. Because any change in local climate and its variability is assumed as it will directly and significantly affect the current and future agriculture (Greg et al. 2010). In addition to that climate change is believed as it will affect human and natural systems in many ways, disrupting food and water supply, exposing them to deadly heat, destroying infrastructure, flooding homes, changing infectious disease vectors, eroding livelihoods, and decreasing economic opportunities (World Bank, 2019).

Table 8: Descriptive statistics and MK trend analysis of seasonal minimum temperature from 1985-2015

\begin{tabular}{|l|c|c|c|c|c|c|c|c|}
\hline Statistic & Mean & SD & CV (\%) & MK test & $\begin{array}{c}\text { p- } \\
\text { value }\end{array}$ & $\begin{array}{c}\text { Sen's } \\
\text { slope }\end{array}$ & $\begin{array}{c}\text { Skewnes } \\
\text { s }\end{array}$ & Kurtosis \\
\hline Spring & 10.99 & 0.81 & 7.33 & 0.52 & 0.0001 & 0.06 & -0.61 & 0.08 \\
\hline Summer & 10.78 & 0.58 & 5.37 & 0.55 & 0.0001 & 0.05 & -0.30 & -0.12 \\
\hline Autumn & 9.27 & 0.53 & 5.68 & 0.55 & & 0.04 & -0.74 & -0.20 \\
\hline Winter & 9.53 & 0.73 & 7.61 & 0.27 & $\mathbf{0 . 0 3 8}$ & 0.03 & -0.30 & 1.38 \\
\hline Annual & 10.05 & 0.54 & 5.41 & 0.57 & & 0.05 & -0.46 & -0.55 \\
\hline
\end{tabular}




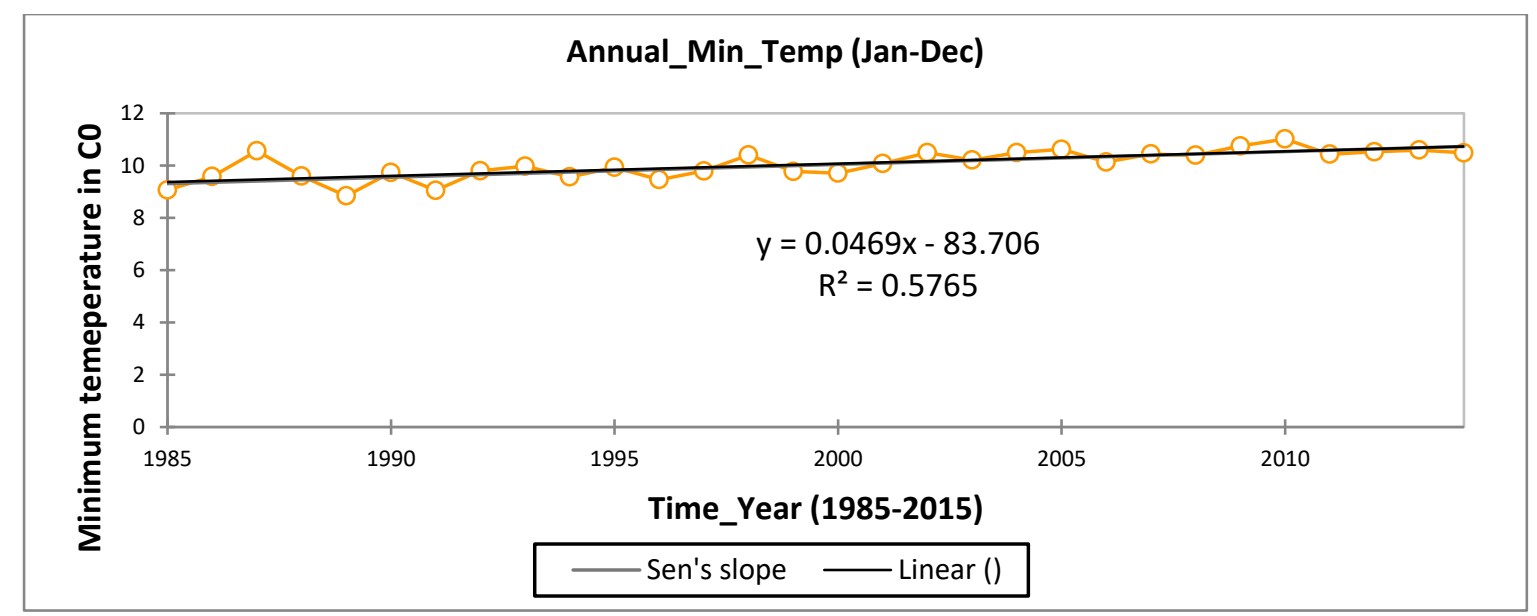

Figure 5: Trend analysis annual mean minimum temperature from 1985-2015

\section{Conclusion and recommendation}

Over the study period 1985 to 2015 , the study finds that the main climatic factors, temperature, and rainfall of the west Shewa zone, Oromia regional state of Ethiopia are showed a changing pattern. The results revealed varying trends of temperature and rainfall over the last three decades both on a monthly and seasonal scale. In view of that, the pattern of rainfall was increasing with the majority of months except in February, March, April, and August, it showed a decreasing trend. Regarding season, in both the spring and winter, the rainfall showed a decreasing trend by $-0.09 \mathrm{~mm}$ and $-0.80 \mathrm{~mm}$, while summer and annual rainfall illustrates an increasing trend by $0.2 \mathrm{~mm}$ and $1.29 \mathrm{~mm}$, respectively. However, the annual rainfall is insignificantly increased by $1.29 \mathrm{~mm}$ and with $10.8 \%$ of the variation for the entire period. The analysis result of skewness exhibits that both the summer and annual rainfall highlighted positively skewed distribution whereas spring, autumn and winter seasons showed moderately skewed distribution of rainfall during the study period. In addition, the result of kurtosis for all months including for four seasons and annual rainfall is below three, showing that the shape of the rainfall distribution curve is platykurtic. This indicates that there were no significant amounts of outlier rainfall in the data set during the study period.

Regarding temperature, both the annual minimum and maximum temperature of the area showed an increasing trend that is significant at a 5\% level of alpha. The result of Sen's slope revealed that the trend of mean minimum and mean maximum temperature of the area was increased by $0.05{ }^{\circ} \mathrm{C}$ and 0.03 ${ }^{\circ} \mathrm{C}$ respectively within the year of consideration. On the other hand, the highest increase in both mean minimum and mean maximum temperature is observed during spring that is by the rate of $0.06{ }^{\circ} \mathrm{C}$ and $0.07{ }^{\circ} \mathrm{C}$ respectively. Generally, the result indicates that the increase in the trend of minimum temperature is moving in highest and the maximum temperature is moving at the lowest rate.

It is therefore recommended that climate change policies are need to be actively mainstreamed into all the developmental plans are either developed by the government or humanitarian organizations. This is an urgent need to support the fundamental strategies of climate change impact emphasizing more on increasing adaption options for farmers because the majority of farmers rely on rain-fed agriculture.

Ethical approval and consent to participate

Consent to participant was received from a university and data providing institution (National Meteorological Agency of Ethiopia).

\section{Consent for publication}

The authors obtained permission from Ambo University. Basically, a research work done by academicians with the help of a University is always expected to be published in the reputable journal as part of duty of the institution for the public.

\section{Availability of data \\ Note relevant for this study}

Competing interests

The authors declare they have no competing interests. 


\section{Funding}

This study was supported by Ambo University especially with logistic facilitation since it is academic institution and it is also the part of duty of academician in a University.

\section{Authors' contributions}

Daniel Assefa designed the data collection tools, undertook fieldwork and most of the analysis, and developed the manuscript. Mesfin Mengistu contributed in developing the data collection tools, survey design and writing of the manuscript. Both authors contributed to the research design, analysis, reviewed and made editorial comments on the draft manuscript. All the authors read and approved the final manuscript.

\section{Acknowledgements}

Special acknowledgments to Ambo University for support during this research project. I would like to thank the National Meteorology Agency for providing the available historical climate records in the area.

\section{Reference}

Agere L.E. 2017. Trend analysis of seasonal rainfall and annual temperature in semi-arid Central lowland of Oromia state, Ethiopia Academic Research Journal of Agricultural Science and Research Vol. 5(7), pp. 509-513, November 2017

Aggarwal V.R.K, P.K. Mahajan, Y.S. Negi, S.K. Bhardwaj. 2015. Trend Analysis of Weather Parameters and People Perception in Kullu District of Western Himalayan Region. Environment and Ecology Research 3(1): 24-33, 2015

Aklilu Mekasha, Kinde Tesfaye and A.J. Duncan. 2014. Trends in daily observed temperature and precipitation extremes over three Ethiopian eco-environments. INTERNATIONAL JOURNAL OF CLIMATOLOGY. Int. J. Climatol. 34: 1990-1999 (2014)

Amogne Asfaw, Belay Simane, Ali Hassen, Amare Bantider. 2018. Variability and time series trend analysis of rainfall and temperature in northcentral Ethiopia: A case study in Woleka sub-basin Weather and Climate Extremes journal homepage: www.elsevier.com/locate/wace

Amogne, A., Belay S., Ali H., Amare B. 2018. Variability and time series trend analysis of rainfall and temperature in northcentral Ethiopia: A case study in Woleka sub-basin. Weather and Climate Extremes 19 (2018) 29-41

Asaminew Teshome Game and Diriba Korecha. 2015. Recent Changes in Rainfall, Temperature and Number of Rainy Days over Northern Oromia Zone, Ethiopia. Science Discovery 2015; 3(6): 62-70

Banacos, Peter C. 2011. Box and whisker plots for local climate datasets: interpretations and creation using excel 2007/2010. Eastern Region Technical Attachment No. 2011-01

Belay, A., Bekele, T., \& Ewunetu, Z. 2013. Analysis of climate variability and its economic impact on agricultural crops: the case of Arsi Negelle district centeral reffty valley of Ethiopia. Open Science Repository Agriculture.

Birhan Getachew. 2018. Trend analysis of temperature and rainfall in south Gonder zone, Ethiopia. JOURNAL OF DEGRADED ANDMINING LANDSMANAGEMENT 5(2): 2502-2458

Birhan, G. 2017. Impacts of climate change on crop yields in south Gonder zone, Ethiopia. World Journal of Agricultural Research 5 (2): 102-110.

Birhanu Hayelom, Yingjun Chen, Zinabu Marsie and Misiker Negash. 2017. Temperature and Precipitation Trend Analysis over the Last 30 Years in Southern Tigray Regional State, Ethiopia. doi:10.20944/preprints201702.0014.v1

Birsan, M., Molnar, P., Burlando, P., Pfaundler, M. 2005. Streamflow trends in Switzerland. Journal of Hydrology, 314, 312-329.

Burn DH, Cunderlik JM, Pietroniro A. 2004. Hydrological trends and variability in the Liard river basin. Hydrological Sciences Journal 49: 53-67.

Daniel Mengistu, Woldeamlak Bewketa and Rattan Lal. 2013. Recent spatiotemporal temperature and rainfall variability and trends over the Upper Blue Nile River Basin, Ethiopia. INTERNATIONAL JOURNAL OF CLIMATOLOGY. Int. J. Climatol. (2013)

Douglas EM, Vogel RM, Knoll CN. 2000. Trends in flood and low flows in the United States: impact of spatial correlation. Journal of Hydrology 240: 90-105.

Fazzini, M., Bisci, C. and Billi, P. 2016. The Climate of Ethiopia. ResearchGate, at: https://www.researchgate.net/publication/295074267

Gebre H, Kindie T, Girma M, Belay K. 2013. Trend and variability of rainfall in Tigray, Northern Ethiopia: analysis of meteorological data and farmers' perception. Acad J Agric Res 1(6):88-100

Ghasemi, A.R. 2015. Changes and trends in maximum, minimum and mean temperature series in Iran. Atmospheric Science Letters, 16, 366-372. https://doi.org/10.1002/asl2.569.

Girma E., Johansson T., and Wayessa G. 2015. Rainfall trend and variability analysis in Setema-Gatira area of Jimma, Southwestern Ethiopia. Academicjournals11(32):3037-3045 
Gogoi P.P. 2019. Time Series Analysis of Temperature and Rainfall over Brahmaputra Basin, Assam. See discussions, stats, and author profiles for this publication at: https://www.researchgate.net/publication/333968478

Greg,P., Ingram, J., and Brklacich, M. 2010, Climate Variability and food security, Philosophical Transaction of the Royal Society B, 2139 - 2148.

Gümüș V., N.G. Soydan, O. Şimșek, H.M. Algin, M.S. Aköz and K.Yenigun. 2017. Seasonal and annual trend analysis of meteorological data in Sanliurfa, Turkey. European Water 59: 131-136, 2017.

Hadju, G., Tesfaye, K., Mamo, G., \& Kassa, B. 2013. "Trend and variability of rainfall in Tigray, Northern Ethiopia: Analysis of meteorological data and farmers’ perception”, Academia Journal of Environmental Sciences, pp.1-13.

Hailu, B., H., Pandey R. P. and S. K. Mishra. 2018. Trend and variability analysis of rainfall and temperature in the Tana basin region, Ethiopia. Journal of Water and Climate Change |09.3| 2018

Hare W. 2003. Assessment of Knowledge on Impacts of Climate Change, Contribution to the Specification of Art, 2 of the UNFCCC, WBGU

HDR (Human Development Report). 2007. Fighting Climate Change: Human solidarity in a divided world.

Helsel DR, Hirsch RM. 1992. Statistical Methods in Water Resources. Elsevier: New York.

Hirsch, R.M., Slack, J.R., Smith, R.A. 1982. Techniques of trend analysis for monthly water quality data. Water Resources Research, 18 (1): 107-121.

Intergovernmental Panel on Climate Change (IPCC). 2007. Climate Change 2007: The Physical Science Basis. Contribution of Working Group I to the Fourth Assessment Report of the Intergovernmental Panel on Climate Change [Solomon, S., D. Qin, M. Manning, Z. Chen, M. Marquis, K.B. Averyt, M.Tignor and H.L. Miller (eds.)]. Cambridge University Press, Cambridge, United Kingdom and New York, NY, USA, 996 pp.

IPCC (Intergovernmental Panel on Climate Change). 1995. A Report of the Intergovernmental Panel on Climate Change. Second Assessment Climate Change 1995

IPCC (Intergovernmental Panel on Climate Change). 2007. Climate change 2007: the physical science basis. Contribution of Working Group I to the Fourth Assessment Report of the Intergovernmental Panel on Climate Change, S. Solomon, et al., eds. Cambridge: Cambridge University Press.

IPCC (Intergovernmental Panel on Climate Change). 2014. Climate Change 2014 Synthesis Report for Policy Makers. Cambridge University Press, Cambridge, United Kingdom and New York, USA, 35.

IPCC (Intergovernmental Panel on Climate Change). 2018. Summary for Policymakers. In: Global warming of $1.5^{\circ} \mathrm{C}$. An IPCC Special Report on the impacts of global warming of $1.5^{\circ} \mathrm{C}$ above preindustrial levels and related global greenhouse gas emission pathways, in the context of strengthening the global response to the threat of climate change, sustainable development, and efforts to eradicate poverty

Issahaku, A., Campion, B.B., and Edziyie, R. 2016. Rainfall and temperature changes and variability in the Upper East Region of Ghana. Earth and Space Science, 3, 284-294,

Jain S. K., V. Kumar and M. Saharia. 2013. Analysis of rainfall and temperature trends in northeast India. INTERNATIONAL JOURNAL OF CLIMATOLOGY. Int. J. Climatol. 33: 968-978 (2013)

Karpouzos, D.K., Kavalieratou, S., Babajimopoulos, C. 2010. Trend analysis of precipitation data in Pieira Region (Greece). European Water, E.W. Publications. 30, 31-40.

Kendall, M.G. 1975. Rank Correlation Measures; Charles Griffin: London, UK.

Koricha D, Viste E, Sorteberg A. 2012. Recent drought and precipitation tendencies in Ethiopia. Theory Appl. Climatol. 112:535-551.

Lewis S.C. and A.D. King. 2016. Evolution of mean, variance and extremes in 21st century temperatures, Weather Clim. Extrem., no. July, p. 1, 2016.

Lupi A and Kibert K. 2019. Analysis of Main Growing Seasonal (Kirmet or Genna) Rainfall and Dry Spell Occurrence in Semi-Arid Central Rift Valley of Oromia Regional State, Ethiopia. Journal of Horticultural Science and Crop Research

Mann HB. 1945. Nonparametric tests against trend. Econometrica 13: 245-259.

Martha K., R. Negeswara R. 2016. “Observed and Projected Rainfall Trends and Variability: A Case Study in Gama Gofa Zone, Ethiopia”, Imperial Journal of Interdisciplinary Research (IJIR).

McSweeney, C., New, M., and Lizcano, G. 2008. UNDP Climate Change Country Profiles - Ethiopia. Available at: http:// country-profiles.geog.ox.ac.uk

Miseker, B.M., Birhanu H., Abrha, Z., Gebru M. 2017. Time Series Trend Analysis of Precipitation and Temperature: The Case of Arba Minch Town, Southern Ethiopia. INTERNATIONAL JOURNAL OF ENGINEERING SCIENCES \& RESEARCHTECHNOLOGY 6(2): February, 2017

NAPA. 2007. Climate Change, National Adaptation Programme of Action Ethiopia. Addis Ababa.

National Meteorological Agency of Ethiopia (NMA). 2007. Climate Change National Adaptation Programme of Action (Napa) Of Ethiopia. The Federal Democratic Republic Of Ethiopia Ministry 
Of Water Resources National Meteorological Agency. Abebe T, National Meteorological Agency. Addis Ababa.

Negash, W., N.K. Goel \& M.K. Jain. 2013. Temporal and spatial variability of annual and seasonal rainfall over Ethiopia, Hydrological Sciences Journal, 58:2, 354-373, DOI: $10.1080 / 02626667.2012 .754543$

NMA (National Meteorological Agency). 2001. Initial National Communication of Ethiopia to the United Nations Framework Convention on Climate Change, Addis Ababa: NMSA

NMA (National Meteorological Agency). 2007. National Meteorology Agency: Final Report on Evaluation Criteria for Identifying High Priority Adaptation Activities prepared by B and M Development Consultants for NMA. Addis Ababa, Ethiopia.

NMA (National Meteorology Agency). 1996. Climatic and Agro climatic Resource of Ethiopia Vol .1. NO.1 National Meteorology Agency of Ethiopia Addis Ababa 137.

Patle G. T. and A. Libang. 2014. Trend analysis of annual and seasonal rainfall to climate variability in North-East region of India. Journal of Applied and Natural Science 6 (2): 480-483 (2014)

Pohlert, T. 2018. Non-Parametric Trend Tests and Change-Point Detection: The R Project for Statistical Computing: Vienna, Austria, 2018.

Prasada-Rao P.V.V. \& Solomon Addisu Legesse. 2014. Trend Analysis and Adaptation Strategies of Climate Change in North Central Ethiopia. International Journal of Agricultural Science and Research (IJASR)

Riche, B., Hachileka, E,. Awuor, C.B., \& Hammill, A. 2009. Climate-related vulnerability and adaptivecapacity in Ethiopia's Borana and Somali communities. Save the Children.

Senait Regassa, Givey, C. and Castillo G.E. 2010. The rain doesn't come on time any more: Poverty, Vulnerability and Climate Variability in Ethiopia. Oxfam International April 2010. 2010.

Singh, P., Kumar, V., Thomas, T., Arora, M. 2008. Basin-wide assessment of temperature trends in Northwest and Central India. Hydrol. Sci. J. 53 (2), 421-433.

Solomon Abirdew Yirga, Girma Mamo \& Mengistu Mengesah. 2017. Rainfall and Temperature Trend Analysis at Indibir Station, Gurage Zone, Ethiopia. Journal of Environment and Earth Science, Vol.7, No.9, 2017

Solomon Addisu, Yihenew G. Selassie, Getachew Fissha and Birhanu Gedif. 2015. Time series trend analysis of temperature and rainfall in Lake Tana Sub-basin, Ethiopia. DOI 10.1186/s40068-0150051-0

Solomon H. Gebrechorkos, Stephan Hülsmann \& Christian Bernhofer. 2019. Long-term trends in rainfall and temperature using high-resolution climate datasets in East Africa. Scientific Research, Naturereport.

Tefera, T. and Agena, A. 2016. Spatio-temporal Variability and Trends of Rainfall and Temperature over Gamo Gofa Zone, Ethiopia. J. Sci. Res. Rep. 2016, 12, 1-11.

Tukey, J.W. 1977. Exploratory Data Analysis. Reading, PA: Addison- Wesley.

UNDP (United Nation Development Program). 2018. Human Development Indicators and Indices: 2018 Statistical Update Team. UN Plaza, New York, NY 10017 USA

Woldeamlak, B., and Conway, D. 2007. A Note on the temporal and spatial variability of rainfall in the drought-prone Amhara Region of Ethiopia. Int. J. Climatol. 27: 1467-1477.

World Bank. 2019. The World Bank Group Action Plan on Climate Change Adaptation and Resilience. Washington, DC: World Bank. (c) World Bank.

World Meteorological Organization (WMO). 2009. Guidelines on Analysis of extremes in a changing climate in support of informed decisions for adaptation. Observing and Information Systems Department. www.wmo.int

Xu, Z.X., Li, J.Y., Liu, C.M. 2007. Long-term trend analysis for major climate variables in the Yellow River basin. Hydrological Processes, 21, 1935-1948.

Yu, Y.S., Zou, S., Whittemore, D. 1993. Non-parametric trend analysis of water quality data of rivers in Kansas. Journal of Hydrology, 150, 61-80.

Yue, S., Hashino, M. 2003. Long term trends of annual and monthly precipitation in Japan. J. Am. Water Resour. Assoc. 39 (3), 587-596.

Zerihun Getachew. 2012. An Analysis of the Impacts of Climate Change on Crop Yield and Yield Variability in Ethiopia. University of Trento, Graduate School of Social Sciences, 12 May 2012 
Figures

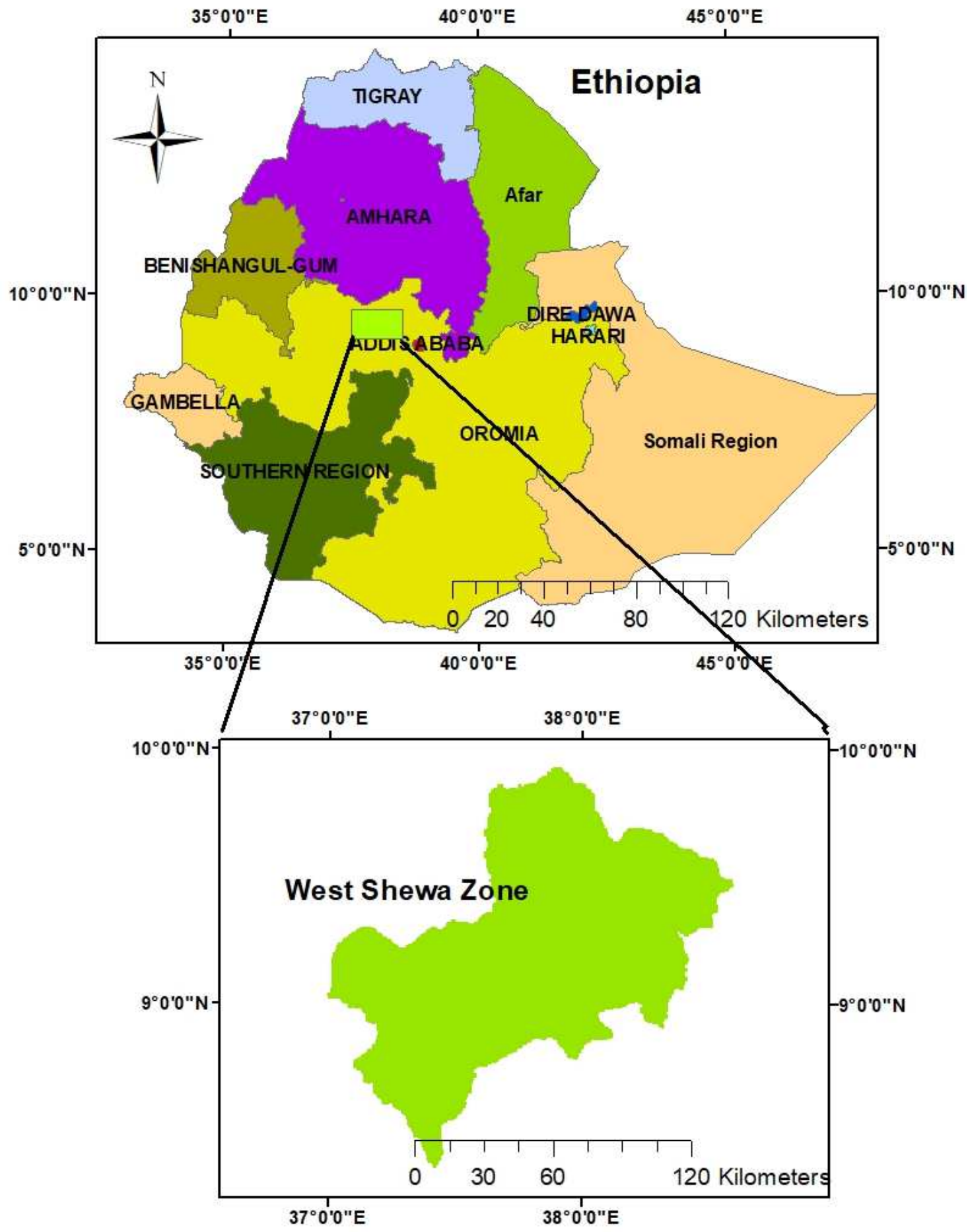

Figure 1

Map of the study area 


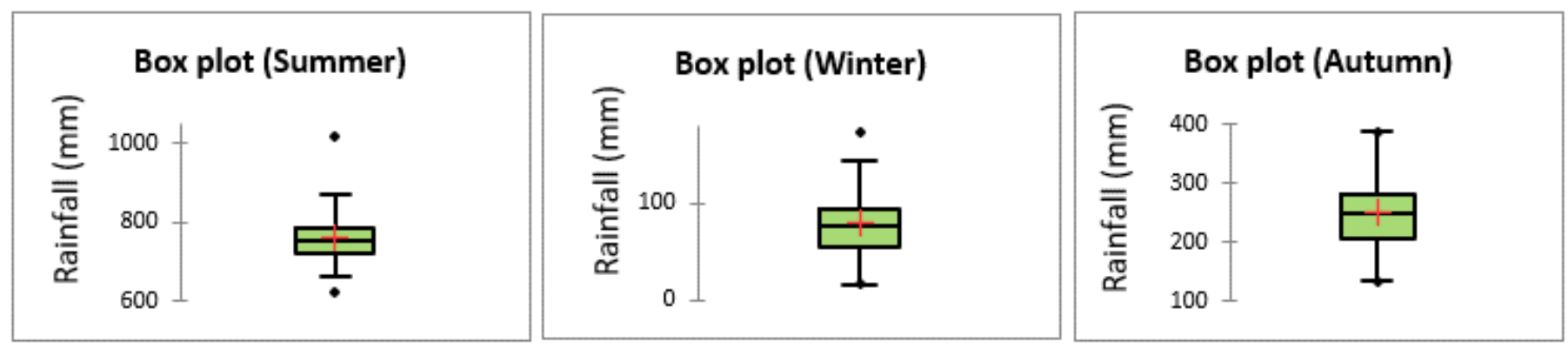

Figure 2

Box plot showing the variability of seasonal rainfall over the study areas for the period 1985-2015 

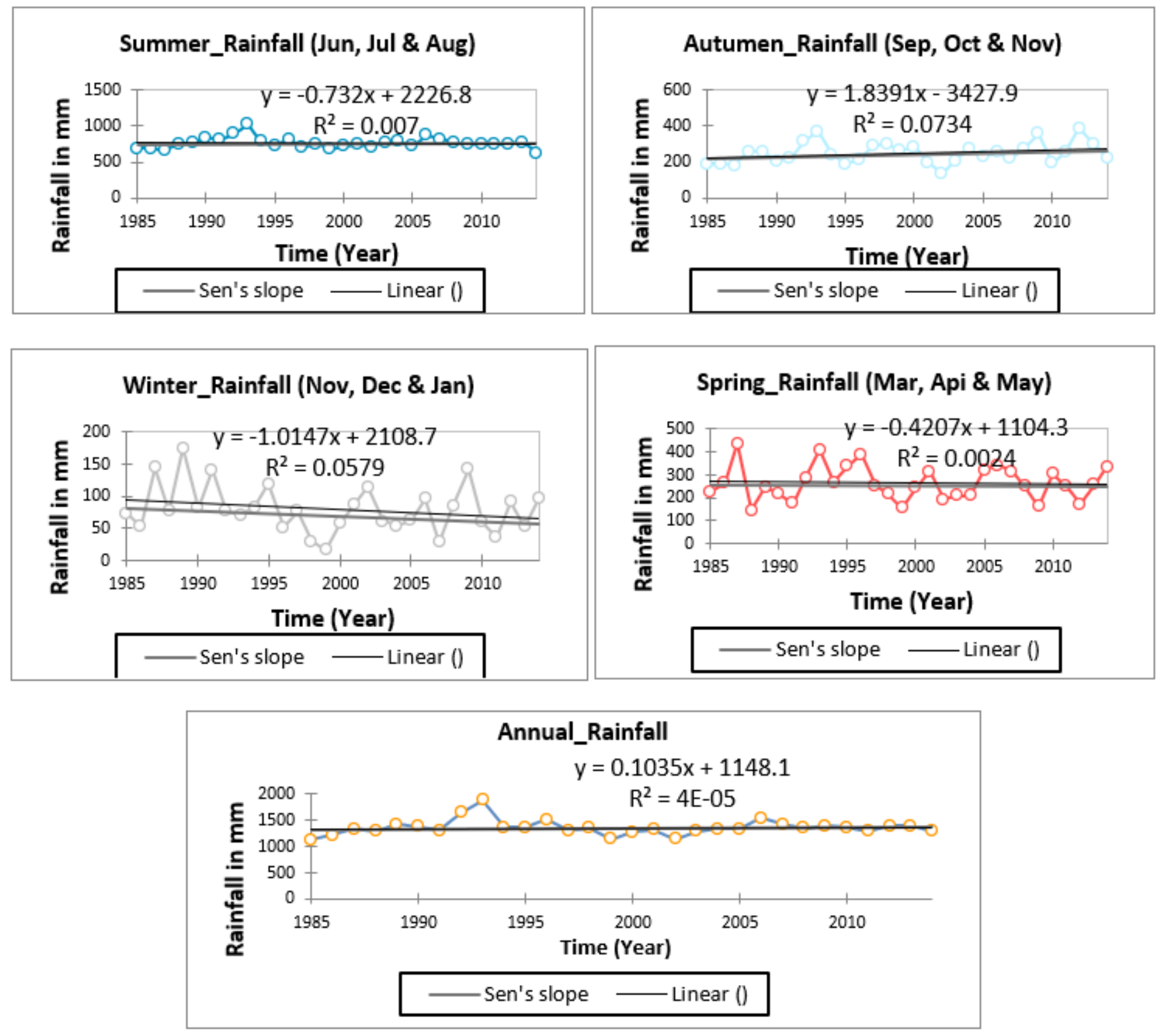

Figure 3

Seasonal trends of rainfall in the study area from 1985-2015 
Annual_Max_Temp (Jan-Dec)

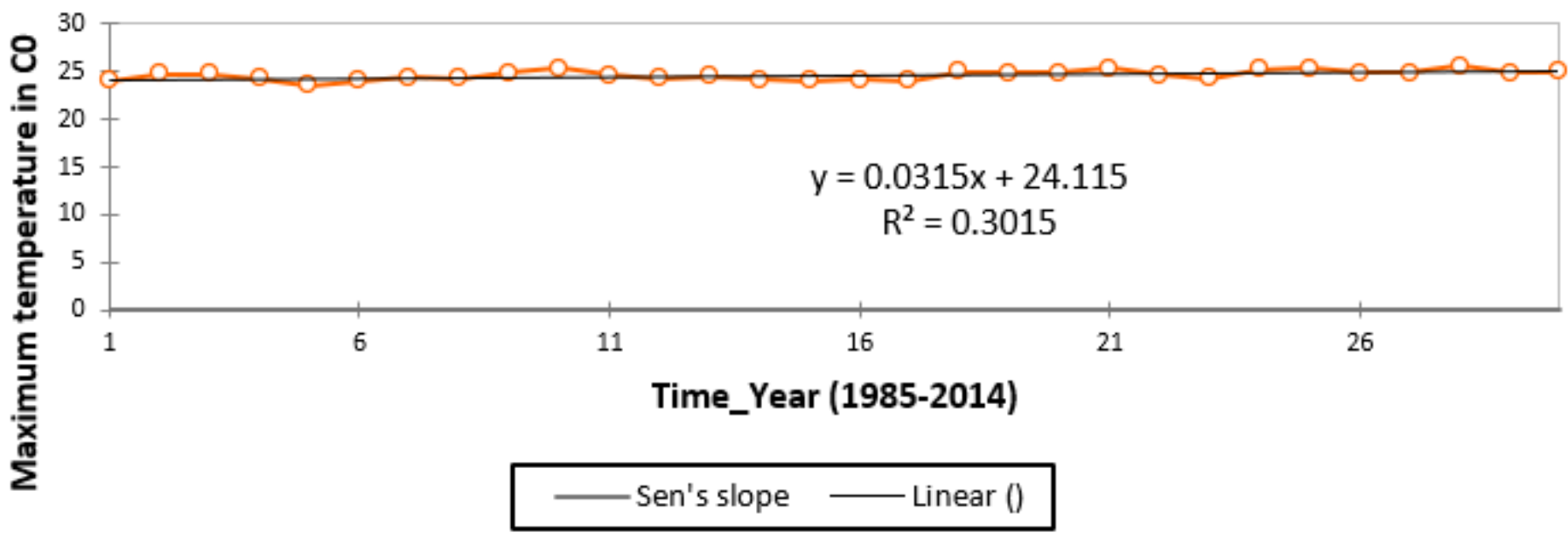

Figure 4

Trend analysis annual mean maximum temperature from 1985-2015

Annual_Min_Temp (Jan-Dec)

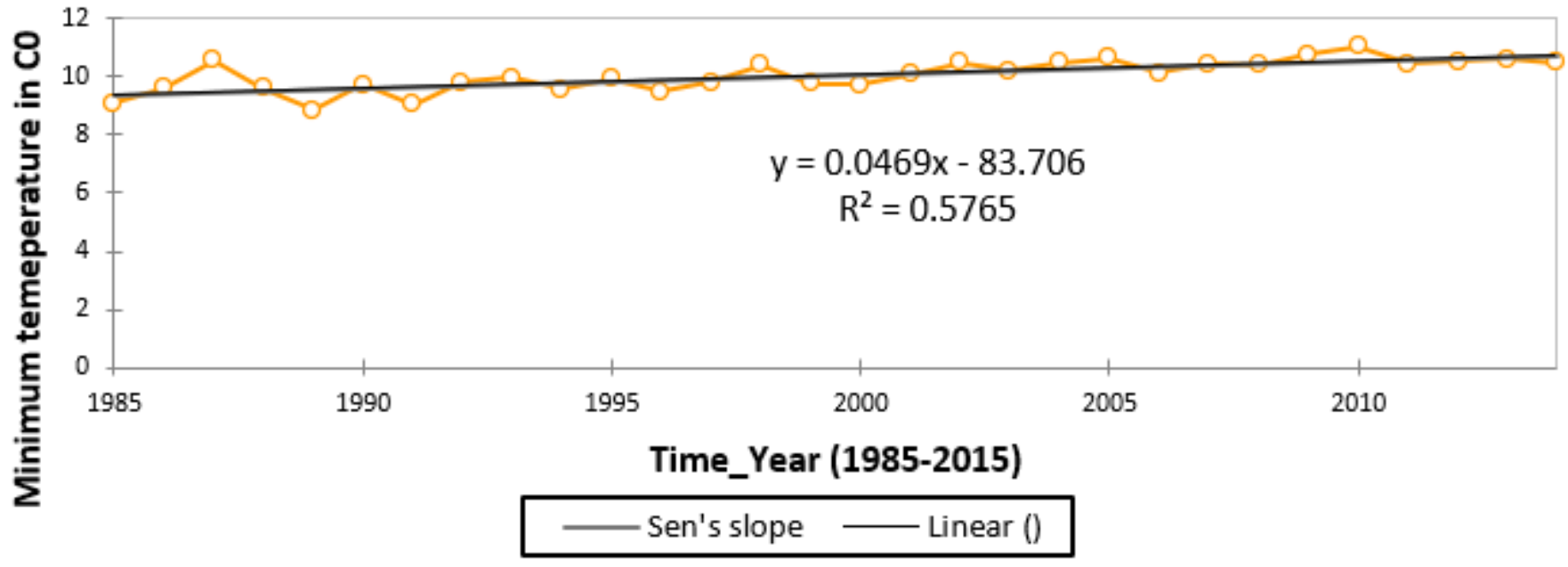

Figure 5

Trend analysis annual mean minimum temperature from 1985-2015 